\section{Dr. Julio Nazer Herrera (1926-2016)}

\section{Julio Nazer M.D. (1926-2016)}

El Dr. Julio Nazer Herrera nació en Salamanca (IV Región) el 26 de marzo de 1926 y murió el 27 de noviembre de 2016. Se tituló de Médico Cirujano en la Universidad de Chile en septiembre de 1951 y se especializó en pediatría y neonatología en la misma Universidad. Se desempeñó como pediatra en el Hospital Roberto del Río entre los años 1952 y 1964 y participó en la creación de la Unidad de Neonatología de la Maternidad del Hospital Clínico de la Universidad de Chile (HCUCH), de la cual fue Jefe entre los años 1964 y 1994 y a la cual continuó concurriendo regularmente durante toda su vida.

Profesor Titular de la Universidad de Chile desde 1998, fue docente de pediatría y neonatología para alumnos e internos de la Escuela de Medicina y de Obstetricia de la Universidad de Chile desde 1959. Fue Profesor de múltiples cursos de postgrado y postítulo especialmente en medicina perinatal y neonatología, y participó en la formación de numerosos médicos académicos de la Universidad de Chile, médicos pediatras especialistas en neonatología, matronas y enfermeras. Se destacó por su entusiasta compromiso con la docencia, no sólo al lado de la cama del enfermo sino también motivando a sus alumnos a participar en trabajos de investigación en el área de la epidemiología de las malformaciones congénitas.

Fue Socio Fundador y Presidente de la Rama de Neonatología de la Sociedad Chilena de Pediatría.

Publicó más de 100 artículos en revistas científicas y presentó innumerables comunicaciones a congresos, por los que recibió distinciones de la Sociedad Chilena de Obstetricia y Ginecología, Premio Geigy (Buenos Aires) y Premio Ramón Corvalán Melgarejo de la Sociedad Médica de Santiago.

Fue editor y autor de numerosos libros y capítulos de libros de pediatría, medicina perinatal y malformaciones congénitas, tema en el que fue un destacado referente nacional.

Fue miembro fundador del ECLAMC (Estudio Colaborativo Latinoamericano de Malformaciones Congénitas); sistema de vigilancia epidemiológica que lleva un registro desde 1967 de anomalías congénitas (integrado al International Clearinghouse for birth defects monitoring system)

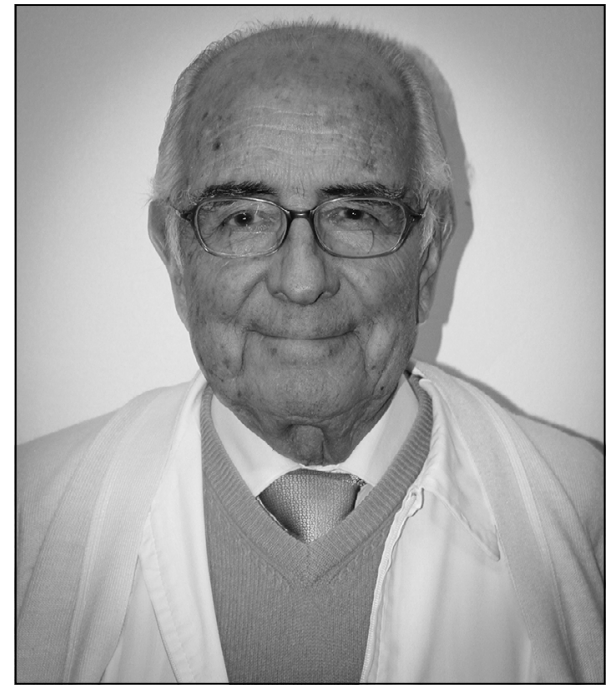

cuya coordinación central reside en Río de Janeiro, Brasil y coordinó dicho estudio en Chile desde 1969, logrando la integración de 24 Hospitales a lo largo del país.

Recibió importantes reconocimientos como homenaje de la Rama de Neonatología de la Sociedad Chilena de Pediatría por su destacada contribución al desarrollo de la neonatología en Chile (2004), nombramiento como miembro emérito del Colegio Médico el año 2001 y presentado por la Facultad de Medicina de la Universidad de Chile para el premio Reina Sofía en el año 1996.

A toda su contribución al desarrollo de la neonatología nacional y al conocimiento de las malformaciones congénitas en nuestro país, debemos agregar su entrega a la docencia, su entusiasmo para involucrar a sus alumnos en sus investigaciones, su generosidad con su conocimiento y la dedicación a sus pequeños pacientes; en él confluían las grandes cualidades de un clínico y la inquietud intelectual de un investigador.

Personalmente, agradezco el privilegio de haber trabajado con él en el ámbito de la epidemiología de las malformaciones congénitas y haber podido compartir sus conocimientos junto a su amabilidad, sencillez, calidez y su valiosa amistad.

Dra. Lucía Cifuentes Ovalle Profesor Titular Facultad de Medicina, Universidad de Chile 